\title{
CULTIVARES, DOSES DE FERTILIZANTES E DENSIDADES DE SEMEADURA NO CULTIVO DE MILHO SAFRINHA ${ }^{1}$
}

\author{
Corn responses to fertilizer rates and sowing densities
}

\author{
José Luiz Andrade Rezende Pereira ${ }^{2}$, Renzo Garcia Von Pinho ${ }^{3}$, Iran Dias Borges ${ }^{4}$, \\ Antonio Marcos Andrade Rezende Pereira ${ }^{5}$, Tiago Geraldo Lima ${ }^{6}$
}

\begin{abstract}
RESUMO
Objetivou-se, neste trabalho, avaliar o desempenho de cinco cultivares de milho submetidas a três densidades de semeadura e duas doses de fertilizantes em Lavras, MG. Foram conduzidos quatro experimentos, sendo dois em 2004 e dois em 2005. Em cada experimento as cinco cultivares (GNZ2005, AG9010, P3041, AG7000 e DKB350) foram avaliadas em três densidades de semeadura $\left(45.000,55.000\right.$ e 65.000 plantas ha ${ }^{-1}$ ) e em duas doses de fertilizantes ( alta dose - $400 \mathrm{~kg} \mathrm{ha}^{-1}$ de $08-28-16+0,5 \% \mathrm{Zn}$, e $90 \mathrm{~kg} \mathrm{ha}{ }^{-1} \mathrm{de}$ $\mathrm{N}$ em cobertura e baixa dose - $200 \mathrm{~kg} \mathrm{ha}^{-1}$ de 08-28-16 + 0,5\% Zn, e $45 \mathrm{~kg} \mathrm{ha}^{-1} \mathrm{de} \mathrm{N}$ em cobertura). Utilizou-se o delineamento blocos casualizados em esquema fatorial, com três repetições. A produtividade de grãos das cultivares foi influenciada apenas pelo ano de avaliação e pela interação anos versus cultivares. As doses de fertilizantes e as densidades de semeadura não influenciaram a produtividade de grãos das cultivares. Há cultivares mais adaptadas às condições de cultivo de milho safrinha na região. No primeiro ano de avaliação, as cultivares DKB 350 e AG 9010 e AG 7000 foram as que apresentaram o melhor desempenho enquanto que no ano de 2005 foram a DKB 350, e GNZ 2005. A adoção da maior dose de fertilizantes não proporciona incrementos significativos na produtividade de grãos de milho, porém provoca redução na porcentagem de plantasacamadas e quebradas. A densidade de 55.000 plantas ha ${ }^{-1}$ proporciona a maior produtividade de grãos.
\end{abstract}

Termos para indexação: Zea mays, milho safrinha, adubação, população de plantas.

\begin{abstract}
This work had the aim of evaluating responses of five corn cultivars to three sowing densities, fertilized with two fertilizer doses, in Lavras, MG, Brazil. Four experiments were carried out, being two in 2004 and two in 2005. Five cultivars (GNZ2005, AG9010, P3041, AG7000, and DKB350) were grown at three sowing densities (45,000; 55,000, and 65,000 plants ha $\left.{ }^{-1}\right)$ and in a fertilizer dose (high dose $-400 \mathrm{~kg} \mathrm{ha}^{-1}$ of $08-28-16+0.5 \% \mathrm{Zn}$, and $90 \mathrm{~kg} \mathrm{ha}^{-1} \mathrm{~N}$ in top dressing or in lower doses - $200 \mathrm{~kg}^{-1}$ of $08-$ $28-16+0.5 \% \mathrm{Zn}$, and $45 \mathrm{~kg} \mathrm{ha}^{-1} \mathrm{~N}$ in top dressing) in each experiment. The experimental design was a randomized block in a factorial scheme with three replications. Higher grain yield was promoted by 55,000 plants ha ${ }^{-1}$ when compared to the other densities; high rates of fertilizers did not promote increase in corn grain yield; the DKB 350, AG 9010, and AG 7000 cultivars showed better performance when compared to the other cultivars tested. Performances of all cultivars were similar regarding the rates of fertilizers and densities, with differences among growing seasons.
\end{abstract}

Index terms: Zea mays, fertilization, plant population.

(Recebido em 28 de março de 2007 e aprovado em 19 de março de 2008)

\section{INTRODUÇÃO}

O milho safrinha é cultivado extemporaneamente, no período de outono/inverno geralmente entre os meses de fevereiro a agosto. Esse cultivo iniciou-se com agricultores do estado do Paraná, no início da década de 1980. Nessa época, a produtividade de grãos era muito baixa e os investimentos em adubação desprezíveis.
Safrinha era sinônimo de risco e baixa tecnologia. Utilizavam-se, geralmente, grãos para a semeadura oriundos de sobras de sementes da safra de verão, independentemente de sua adaptação às condições de cultivo da safrinha (DUARTE, 2004).

Atualmente, a produção de milho safrinha representa cerca de $30 \%$ da produção total de milho no Brasil e os produtores, a cada ano, investem mais em

\footnotetext{
${ }^{1}$ Parte da dissertação de mestrado do primeiro autor

${ }^{2}$ Engenheiro Agrônomo, Mestre - Departamento de Agricultura/DAG - Universidade Federal de Lavras/UFLA - Cx. P. 3037 - $37200-000$ jlarpufla@yahoo.com.br

${ }^{3}$ Engenheiro Agrônomo, Doutor, Professor Adjunto - Departamento de Agricultura/DAG - Universidade Federal de Lavras/UFLA - Cx. P. 3037 - $37200-000$ renzo@ufla.br

${ }^{4}$ Engenheiro Agrônomo, Doutor em Fitotecnia, Professor - Departamento de Ciências Agrárias - Universidade Estadual de Montes Claros/UNIMONTES Avenida Reinaldo Viana, 2630 - Localidade Bico da Pedra - Cx. P. 91 - 39440-000 - Janaúba, MG - iran.borges@unimontes.br

${ }^{5}$ Engenheiro Agrônomo, Mestre - Avenida Belo Horizonte, 140 - João Paulo II - 37550-000 - Pouso Alegre, MG - antoniomarcosandrade@yahoo.com.br ${ }^{6}$ Engenheiro Agrônomo, Mestre - Avenida Belo Horizonte, 140 - João Paulo II - 37550-000 - Pouso Alegre, MG - tiagogeraldolima@hotmail.com
} 
tecnologia. Os principais estados produtores de milho safrinha são: Mato Grosso, Paraná, Mato Grosso do Sul, São Paulo e Goiás (CONAB, 2007).

Apesar da região sul de Minas ser considerada apta para o cultivo do milho safrinha, esse cultivo é ainda muito incipiente na região. A possibilidade de cultivo do milho safrinha na região sul de Minas Gerais, possibilitará o incremento na renda do agricultor e uma ocupação mais intensiva das terras da região (SANS et al., 1999).

O cultivo do milho safrinha é fortemente influenciado pelos fatores climáticos. A cultura do milho exige um mínimo de $350-500 \mathrm{~mm}$ de precipitação para que produza a contento, sem a necessidade da utilização de irrigação. A falta de água interfere na síntese de proteína e RNA, resultando no aumento da quantidade de aminoácidos livres. $\mathrm{O}$ estresse hídrico pode reduzir a altura da planta, bem como a produção e a fertilidade do pólen, além de alterar o sincronismo do florescimento masculino e feminino (FANCELLI \& DOURADO NETO, 2000; BRASIL et al., 2007).

Além dos fatores climáticos, a época de semeadura, a escolha de cultivares, o manejo da adubação e da população de plantas afetam sobremaneira o cultivo de milho safrinha. Quanto mais tarde for semeado, menor será o potencial produtivo e maior o risco de perdas por geadas e/ou seca. Assim, o planejamento da safrinha começa com a cultura de verão, visando liberar a área o mais cedo possível para a segunda cultura (GALVÃO \& MIRANDA, 2004).

A escolha da cultivar para o cultivo do milho safrinha deverá fundamentar-se na adequação de suas necessidades térmicas à época de semeadura e a região considerada. É importante ressaltar que esses fatores poderão acarretar prolongamento ou redução da fase vegetativa da cultura, comprometendo o desempenho e o potencial de produção (FANCELLI \& DOURADO NETO, 2000). Silva et al. (1997) avaliaram cultivares de ciclos normal, precoce e super-precoce, no estado de Goiás, e observaram que as cultivares com melhor desempenho, foram as de ciclo precoce e super precoce. Duarte et al. (1994) e Viégas (1989), também verificaram em seus trabalhos, um melhor desempenho na safrinha de cultivares de ciclo mais curto.

Experimentos realizados na região do médio Vale do Paranapanema, no estado de São Paulo na safrinha, em 1993, com três cultivares de milho, com densidade de 55.000 plantas por hectare, no período do verão, mostraram que não houve interação entre cultivares e população de plantas, sendo os rendimentos máximos obtidos entre 42 e 50 mil plantas por hectare (DUARTE et al., 1994).
Gonzales Altuna (2000) comparou três métodos de adubação: sem adubação de semeadura, com adubação de semeadura (300 $\mathrm{kg} \mathrm{ha}^{-1}$ da fórmula 04:30:16 $+0,5 \% \mathrm{Zn}$ ) e com adubação de semeadura mais uma cobertura de $300 \mathrm{~kg} \mathrm{ha}^{-1}$ de sulfato de amônio, em dois anos agrícolas distintos (1996 e 1997) e concluiu que a adubação de semeadura do milho safrinha é tecnicamente viável; porém a adubação de cobertura não proporciona acréscimos significativos na produção de grãos de milho.

Há carência em pesquisas na região do sul de Minas Gerais que possibilitem obter informações úteis aos produtores, principalmente no que se refere à avaliação de cultivares e tratos culturais na safrinha. Essas informações permitirão a intensificação no uso da terra, possibilitando que os agricultores maximizem seus lucros e melhorem a sua qualidade de vida.

Objetivou-se, neste trabalho, avaliar cinco cultivares de milho submetidas a três densidades de plantas e duas doses de adubação em dois anos agrícolas, nas condições de safrinha em Lavras, MG.

\section{MATERIAL E MÉTODOS}

Foram utilizados cinco cultivares comerciais de milho de diferentes bases genéticas, tipo de grão, ciclo, porte e adaptados à região sul de Minas Gerais, provenientes de diferentes empresas produtoras de sementes (Tabela 1). Essas cultivares foram escolhidas em função de serem cultivadas pelos agricultores da região e também por serem recomendadas para o cultivo do milho safrinha.

Os experimentos foram conduzidos em área experimental do Departamento de Agricultura da Universidade Federal de Lavras (UFLA), no período da entressafra (safrinha), durante os meses de fevereiro a agosto, dos anos de 2004 e 2005. As variações na temperatura e na precipitação média por decêndio, ocorridas durante a condução dos experimentos estão apresentadas nas Figuras 1 e 2.

A área experimental possui solo de textura argilosa, considerado de alta fertilidade, o que dispensou correção prévia. Essa área vem sendo cultivada com milho há vários anos, e encontrava-se em pousio desde o verão anterior e coberta com espécies daninhas que foram roçadas e incorporadas.

A pesquisa constou de quatro experimentos conduzidos em dois anos de cultivo (2004 e 2005). Em cada ano, foram conduzidos dois experimentos, sendo um com alta dose de fertilizantes ( $400 \mathrm{~kg} \mathrm{ha}^{-1}$ de 08-28-16+0,5\% $\mathrm{Zn}$, e $90 \mathrm{~kg} \mathrm{ha}^{-1}$ de $\mathrm{N}$ em cobertura) e o outro com baixa 
Tabela 1 - Características das cultivares de milho utilizadas nos experimentos. UFLA, Lavras, MG, 2009.

\begin{tabular}{lccccc}
\hline \multicolumn{1}{c}{ Cultivar } & Base genética & Ciclo & Grão & Porte & Empresa \\
\hline GNZ 2005 & Triplo & Precoce & Semiduro & Baixo & Geneze \\
AG 9010 & Simples & Super precoce & Duro & Baixo & Monsanto \\
P 3041 & Triplo & Precoce & Duro & Alto & Pioneer \\
AG 7000 & Simples & Semi precoce & Semiduro & Alto & Monsato \\
DKB 350 & Triplo & Precoce & Semiduro & Médio & Monsanto \\
\hline
\end{tabular}

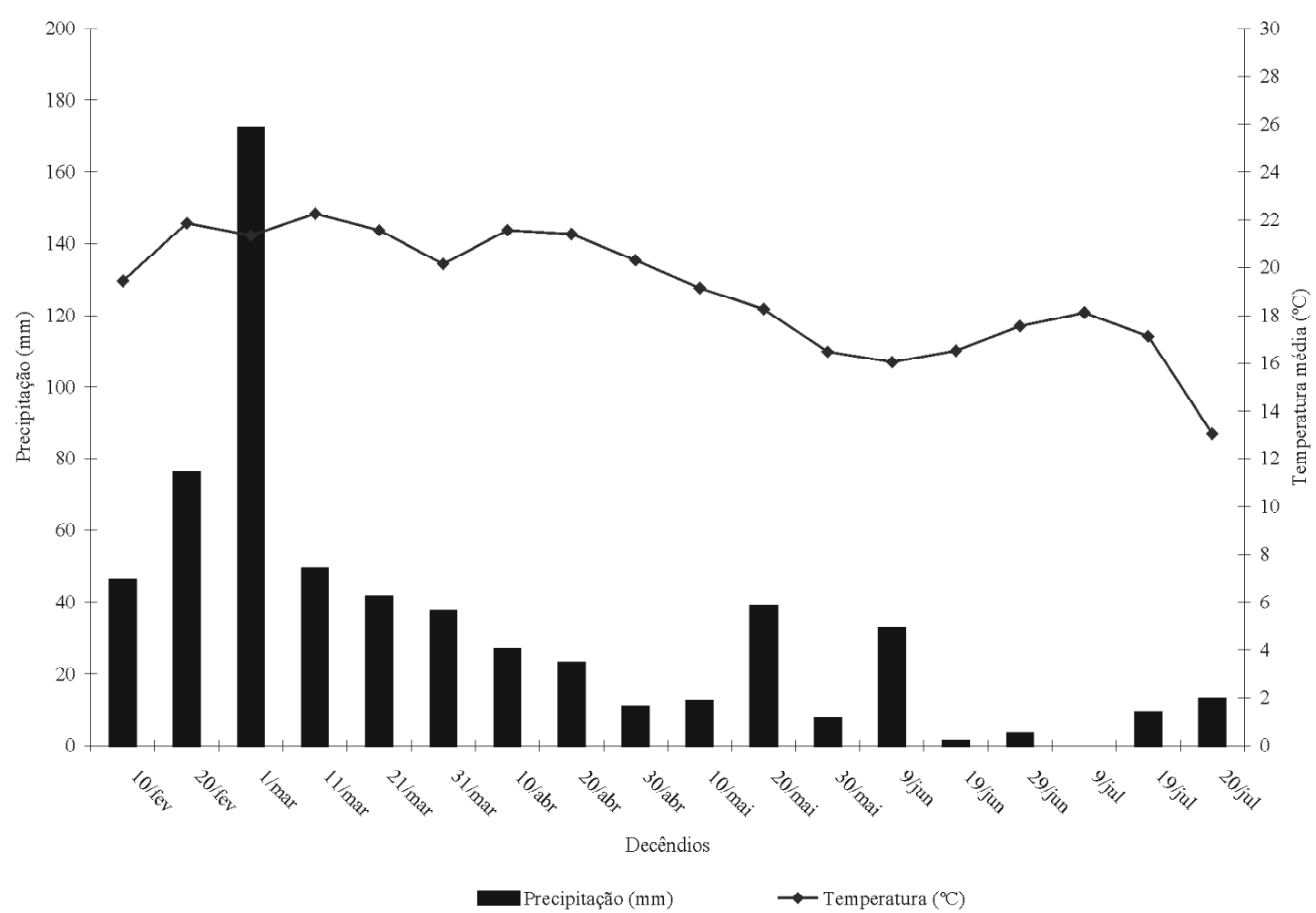

Figura 1 - Dados médios de temperatura e precipitação acumulada por decêndio, em Lavras, MG, de 01/02/2004 a 29/07/ 2004. UFLA, Lavras, MG, 2009.

dose de fertilizantes $\left(200 \mathrm{~kg} \mathrm{ha}^{-1}\right.$ de $08-28-16+0,5 \% \mathrm{Zn}$, e $45 \mathrm{~kg} \mathrm{ha}^{-1} \mathrm{de} \mathrm{N}$ em cobertura). Em cada experimento, as cinco cultivares foram avaliadas em três densidades de semeadura $\left(45.000,55.000\right.$ e 65.000 plantas ha $\left.{ }^{-1}\right)$. Utilizouse o delineamento blocos casualizados em esquema fatorial com três repetições.

$\mathrm{Na}$ área experimental, foram realizadas duas gradagens para destorroamento e nivelamento do solo. Posteriormente foi feito o sulcamento no espaçamento de 0,80 metros entre fileiras. $O$ controle de plantas daninhas foi feito com o uso de atrazina na dosagem de 4,0 $1 \mathrm{ha}^{-1}, 15$ dias, após a emergência das plantas.
Nos dois anos, a semeadura foi realizada manualmente na última semana de fevereiro e as densidades foram definidas após o desbaste, quando as plantas se encontravam com 3 a 4 folhas totalmente expandidas. A adubação nitrogenada de cobertura foi realizada manualmente, com a incorporação a $3,0 \mathrm{~cm}$ de profundidade, quando as plantas se encontravam com 5 a 6 folhas totalmente expandidas. Foi utilizado como fonte de $\mathrm{N}$ o sulfato de amônio. $\mathrm{O}$ controle de insetos de parte aérea foi feito com Decis na dosagem de $200 \mathrm{ml} \mathrm{ha}^{-1}$. Nos dois anos, a colheita foi realizada na primeira semana de agosto. 


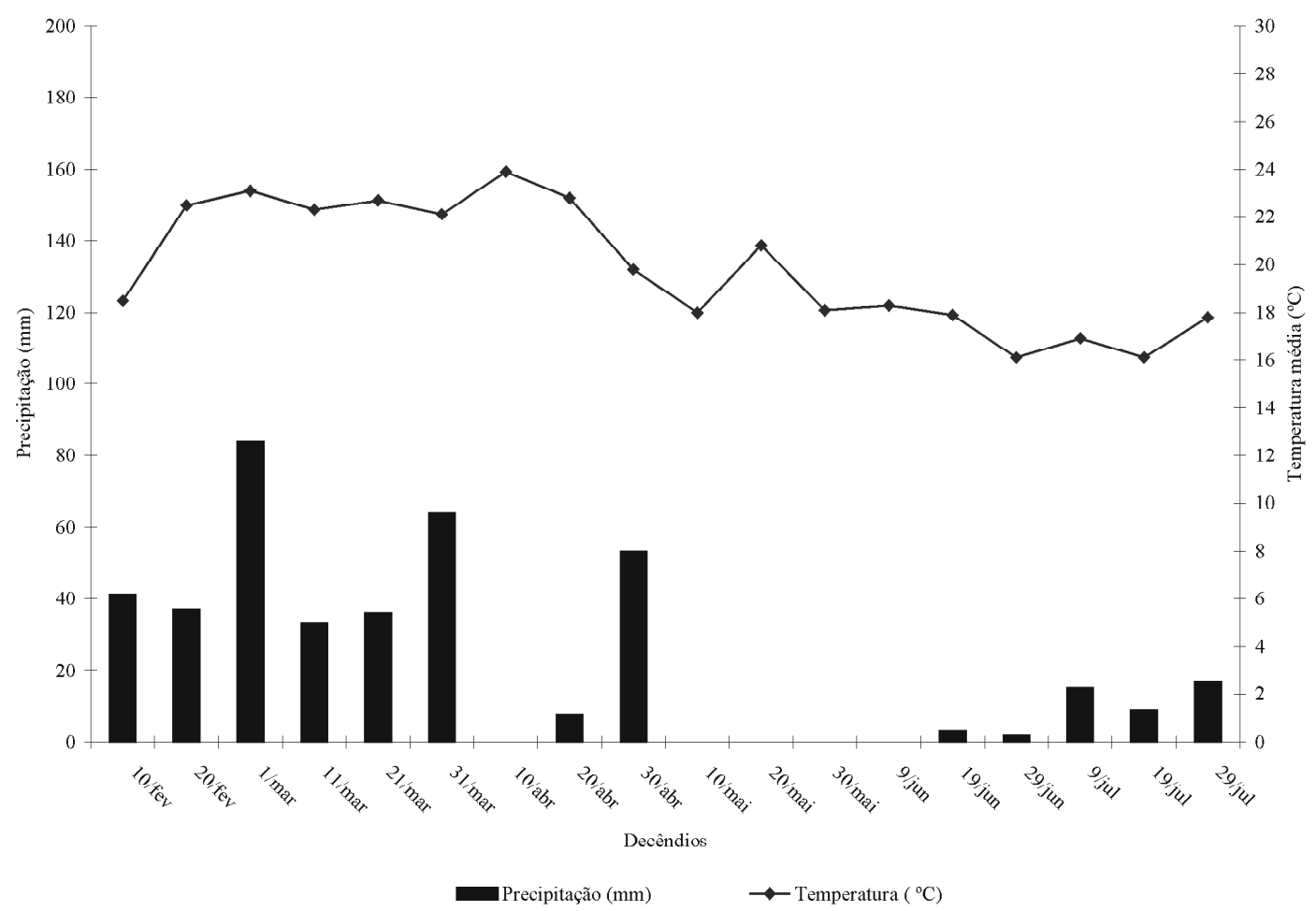

Figura 2 - Dados médios de temperatura e precipitação acumulada por decêndio, em Lavras, MG, de 01/02/2005 a 29/07/ 2005. UFLA, Lavras, MG, 2009.

Cada parcela constou de quatro linhas de 5,0 m, sendo as duas centrais consideradas como úteis, para efeito de coleta dos dados de produtividade de grãos e porcentagens de plantas acamadas e quebradas.

As variáveis analisadas foram a produtividade de grãos e a porcentagem de plantas acamadas e quebradas. $\mathrm{O}$ peso de grãos das parcelas experimentais foi transformado para $\mathrm{kg} \mathrm{ha}^{-1}$ e foram corrigidos para a unidade padrão de $13 \%$. A porcentagem de plantas acamadas e quebradas foi obtida somando-se, na área útil da parcela, as plantas inclinadas, formando um ângulo inferior a $20^{\circ} \mathrm{com}$ o solo, mais o número de plantas quebradas abaixo da espiga. Esse somatório foi expresso em porcentagem do estande observado na área útil da parcela.

Foi realizada uma análise conjunta envolvendo os quatro experimentos. Todas as análises, incluindo o estudo de regressão para a produtividade de grãos em função dos diferentes níveis da variável densidade, foram realizadas utilizando o programa estatístico SISVAR (FERREIRA, 1999).

\section{RESULTADOS E DISCUSSÃO}

A produtividade média de grãos, considerando os quatro experimentos nos dois anos, foi de $3897 \mathrm{~kg} \mathrm{ha}^{-1}$. Esse resultado é considerado alto para essa época de cultivo, pois a produtividade média brasileira do milho safrinha nos últimos cinco anos variou de 2142 a $3592 \mathrm{~kg} \mathrm{ha}^{-1}$ (CONAB, 2007). O resultado demonstra a potencialidade da região para o cultivo do milho safrinha e é semelhante aos resultados obtidos por Gonzales Altuna (2000), que também obteve produtividades de grãos superiores a $2500 \mathrm{~kg} \mathrm{ha}^{-1}$. Vale ressaltar que os valores obtidos são superiores aos obtidos por outros autores em experimentos conduzidos na safrinha (LIMA et al., 2005; MOLTOCARO \& DUARTE, 2005).

É importante enfatizar que a redução na produção de grãos na safrinha, quando comparado com a época normal de cultivo, é devido à ocorrência de déficits hídricos, que diminui a taxa fotossintética e a multiplicação celular, provocando redução da matéria verde total da planta (VALOIS, 1992).

O cultivo de milho safrinha é fortemente influenciado pelos fatores climáticos (temperatura, luz e principalmente a precipitação), portanto era de se esperar que o efeito de anos fosse significativo e influenciasse a produtividade média dos experimentos, visto que as condições climáticas variaram muito de um ano para outro (Figuras 1 e 2). A produtividade média de grãos obtida no ano de 2004 foi superior em 53\% à obtida no ano de 2005 
(Tabela 2). Isso ocorreu, principalmente devido a uma maior precipitação ocorrida em 2004 desde o pré-plantio até a colheita dos experimentos (Figuras 1 e 2, Tabela 3 ).

Tabela 2 - Produtividade média de grãos $\left(\mathrm{kg} \mathrm{ha}^{-1}\right)$, em dois anos considerando cinco cultivares de milho, avaliadas em três densidades de semeadura e duas doses de adubação. UFLA, Lavras, MG, 2009.

\begin{tabular}{cc}
\hline Ano & Médias \\
\hline 2005 & $3081,9 \mathrm{~b}$ \\
2004 & $4711,4 \mathrm{a}$ \\
\hline
\end{tabular}

Médias seguidas de letras distintas diferem entre si pelo teste de $\mathrm{F},(\mathrm{P} \leq 0,05 \%)$.

A soma das normais climatológicas de fevereiro a agosto da região sudeste, sudoeste e sul do estado de Goiás são: $548 \mathrm{~mm}, 627 \mathrm{~mm}$ e $553 \mathrm{~mm}$, respectivamente. Essas regiões são destaque no Brasil na produção de milho safrinha (RIBEIRO et al., 2005). Esses dados pluviométricos estão próximos aos ocorridos em Lavras, MG, o que demonstra a potencialidade da região para o cultivo do milho safrinha (Tabela 3).

A produtividade de grãos foi influenciada pelos fatores anos, densidades de semeadura, cultivares e pela interação anos x cultivares. A precisão experimental avaliada pelo coeficiente de variação foi considerada boa para a produtividade de grãos $(\mathrm{CV}=21,5 \%)$. É de se esperar que a precisão experimental seja mais baixa em experimentos conduzidos na safrinha, devido à ocorrência de estresses ambientais.

Com relação às doses de fertilizantes utilizadas, os resultados obtidos permitem inferir que, para a condição de plantio na safrinha em Lavras, MG, a adoção da alta dose de fertilizante, não proporcionou resposta significativa na produtividade de grãos de milho, em comparação à produtividade alcançada quando se adotou a menor dose de fertilizante. Esse resultado concorda com os obtidos por outros autores (BROCH, 1999; CANTARELLA \& DUARTE, 1997; GONZALES ALTUNA,
2000), que também verificaram que não há resposta significativa quando se utiliza altas doses de adubação para o cultivo de milho safrinha. Vale ressaltar que o potencial produtivo das cultivares fica limitado em função das baixas precipitações que ocorrem durante o ciclo da cultura nessa época de cultivo.

Analisando a produtividade de grãos em função das três densidades de semeadura, verifica-se que houve uma resposta quadrática no peso de grãos, em relação ao aumento da densidade de semeadura, atingindo um máximo próximo a densidade de 55000 plantas ha ${ }^{-1}$ (Figura 3 ). Esses resultados permitem inferir que a densidade de 55000 plantas ha- é mais vantajosa, por proporcionar produtividades maiores que a de 45000 plantas ha-1 $\mathrm{e}$ semelhantes à de 65000 plantas ha $^{-1}$, a qual implica em um maior gasto com sementes. Esses resultados são semelhantes aos obtidos por outros autores (DUARTE, 1995; FANCELLI \& DOURADO NETO, 2000).

Fancelli \& Dourado Neto (2000), verificaram que, em condições de safrinha, populações de plantas entre 45.000 a 55.000 plantas por hectare têm se mostrado mais adequadas, principalmente em função da probabilidade de ocorrência de veranico, do nível de fertilidade do solo e da cultivar utilizada.

O efeito significativo da interação anos x cultivares indica que o comportamento das cultivares foi diferente nos dois anos (Tabela 4). No ano de 2004, as cultivares DKB 350, AG 7000 e AG 9010 apresentaram um comportamento semelhante e superior às demais. Já em 2005, as cultivares de melhor desempenho foram a DKB 350, AG 7000 e GNZ 2005 (Tabela 4). Considerando os dois anos de avaliação, as cultivares de melhor desempenho foram a DKB 350 e AG 7000 (Tabela 4).

Todas as cultivares avaliadas tiveram pior desempenho no ano de 2005, refletindo a menor produtividade de grãos obtida nesse ano decorrente de condições climáticas adversas, durante a condução dos experimentos (Figuras 1 e 2).

A porcentagem de plantas acamadas e quebradas foi influenciada pela dose de fertilizantes e pela interação entre densidades $\mathrm{x}$ cultivares.

Tabela 3 - Precipitações pluviométricas e normais climatológicas ocorridas durante a condução dos experimentos. UFLA, Lavras, MG, 2009.

\begin{tabular}{ccccccccc}
\hline \multirow{2}{*}{ Ano } & \multicolumn{7}{c}{ Mês } \\
\cline { 2 - 8 } & fev. & mar. & abr. & mai. & jun. & jul. & ago. & Total (mm) \\
\hline 2004 & 295,0 & 128,2 & 60,6 & 59,0 & 35,5 & 22,2 & 2,2 & 602,7 \\
2005 & 161,7 & 132,9 & 60,6 & 84,6 & 4,7 & 40,4 & 4,10 & 489,0 \\
Normais $^{*}$ & 192,3 & 174,0 & 67,0 & 40,6 & 27,9 & 23,4 & 24,8 & 550,0 \\
\hline
\end{tabular}

Fonte: Dados obtidos no setor de Agrometeorologia da UFLA, Lavras, MG, 2007.

*As normais climatológicas são as médias de precipitação ocorridas em cada mês no município de Lavras, MG entre os anos de 1961 e 1990. 


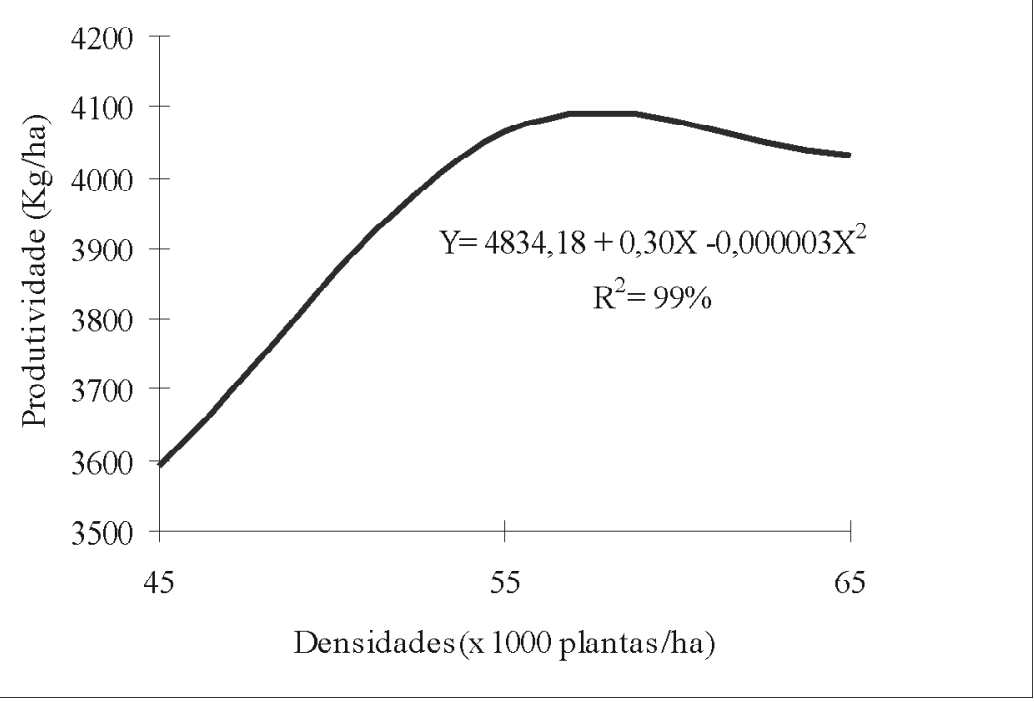

Figura 3 - Representação gráfica da equação de regressão para o efeito de densidades de semeadura na produtividade de grãos de milho. UFLA, Lavras, MG, 2009.

Tabela 4 - Produtividade de grãos $\left(\mathrm{kg} \mathrm{ha}^{-1}\right)$ de cinco cultivares de milho, em função de dois anos de avaliação. UFLA, Lavras, MG, 2009.

\begin{tabular}{cccc}
\hline \multirow{2}{*}{ Cultivares } & \multicolumn{3}{c}{ Ano } \\
\cline { 2 - 4 } & 2004 & 2005 & Média \\
\hline P 3041 & $3849,15 \mathrm{~b} \mathrm{~A}$ & $2588,93 \mathrm{~b} \mathrm{~B}$ & $3219,04 \mathrm{c}$ \\
GNZ 2005 & $4320,09 \mathrm{~b}$ A & $3189,96 \mathrm{a} \mathrm{B}$ & $3755,02 \mathrm{~b}$ \\
AG 9010 & $4925,45 \mathrm{a} \mathrm{A}$ & $2441,54 \mathrm{~b} \mathrm{~B}$ & $3683,50 \mathrm{~b}$ \\
AG 7000 & $4988,96 \mathrm{a} \mathrm{A}$ & $3713,20 \mathrm{a} \mathrm{B}$ & $4351,08 \mathrm{a}$ \\
DKB 350 & $5473,24 \mathrm{a} \mathrm{A}$ & $3475,72 \mathrm{a} \mathrm{B}$ & $4474,48 \mathrm{a}$ \\
\hline
\end{tabular}

Médias seguidas de letras minúsculas distintas na coluna diferem entre si pelo teste de Scott-Knott $(\mathrm{P} \leq 0,05 \%)$ e médias seguidas de letras maiúsculas distintas na linha diferem entre si pelo teste de $\mathrm{F}(\mathrm{P} \leq 0,05 \%)$

No experimento que recebeu a maior dose de fertilizantes, a porcentagem de plantas acamadas e quebradas foi inferior à obtida no experimento que recebeu a menor dose de fertilizantes (Tabela 5). Gonzales Altuna (2000) também verificou uma menor porcentagem de plantas acamadas e quebradas quando se utiliza a maior dose de fertilizante.

As cultivares AG 7000 e P 3041 tiveram a porcentagem de plantas acamadas e quebradas semelhantes e inferiores às demais, na densidade de 45.000 plantas $\mathrm{ha}^{-1}$ (Tabela 6). Na densidade de 55.000 plantas ha $^{-1}$, as cultivares AG 7000, GNZ 2005 e DKB 350 tiveram a porcentagem de plantas acamadas e quebradas semelhantes entre si e inferiores às demais. Já na densidade de 65.000 plantas ha $^{-1}$, foram verificadas diferenças entre as cultivares (Tabela 6). $\mathrm{O}$ aumento na densidade de semeadura não proporcionou acréscimos significativos na porcentagem de plantas acamadas e quebradas.

Tabela 5 - Porcentagem média de plantas acamadas e quebradas considerando duas doses de fertilizantes, três densidades de semeadura e cinco cultivares de milho, avaliadas em dois anos. UFLA, Lavras, MG, 2009.

\begin{tabular}{cc}
\hline Doses de fertilizantes $^{1}$ & Médias \\
\hline Alta dose & $2,89 \mathrm{~b}$ \\
Baixa dose & $4,18 \mathrm{a}$ \\
\hline
\end{tabular}

Médias seguidas de letras distintas diferem entre si, pelo teste de $\mathrm{F}(\mathrm{P} \leq 0,05 \%)$.

${ }^{1}$ Alta dose $-400 \mathrm{~kg} \mathrm{ha}^{-1}$ de $8-28-16+0,5 \% \mathrm{Zn}$ e $90 \mathrm{~kg} \mathrm{ha}^{-1}$ de N em cobertura.

Baixa dose - $200 \mathrm{~kg} \mathrm{ha}^{-1}$ de 8-28-16 + 0,5\% Zn e $45 \mathrm{~kg} \mathrm{ha}^{-1} \mathrm{de}$ $\mathrm{N}$ em cobertura. 
Tabela 6 - Porcentagem média de plantas acamadas e quebradas considerando três densidades de semeadura e cinco cultivares de milho avaliadas em dois anos. UFLA, Lavras, MG, 2009.

\begin{tabular}{cccc}
\hline \multirow{2}{*}{ Cultivares } & \multicolumn{3}{c}{ Densidades $\left(\mathrm{pl} \mathrm{ha}^{-1}\right)$} \\
\cline { 2 - 4 } & 45000 & 55000 & 65000 \\
\hline AG 7000 & 1,41 a A & 1,04 a A & 4,17 a A \\
P 3041 & 2,27 a A & $5,01 \mathrm{~b} \mathrm{~A}$ & 5,26 a A \\
GNZ 2005 & 4,18 b A & 2,44 a A & 3,00 a A \\
AG 9010 & 4,80 b A & $4,82 \mathrm{~b} \mathrm{~A}$ & 2,72 a A \\
DKB 350 & 5,43 b A & 2,54 a A & 3,94 a A
\end{tabular}

Médias seguidas de letras minúsculas distintas na coluna e maiúsculas na linha diferem entre si, pelo teste de Scott-Knott $(\mathrm{P} \leq 0,05)$ e médias seguidas de letras maiúsculas distintas na linha diferem entre si, pelo teste de $\mathrm{F}(\mathrm{P} \leq 0,05)$.

\section{CONCLUSÕES}

A produtividade de grãos das cultivares foi influenciada apenas pelo anos de avaliação e pela interação anos versus cultivares.

As doses de fertilizantes e as densidades de semeadura avaliadas não influenciaram a produtividade de grãos das cultivares.

Há cultivares mais adaptadas às condições de cultivo de milho safrinha na região. No primeiro ano de avaliação, as cultivares DKB 350 e AG 9010 e AG 7000 foram as que apresentaram o melhor desempenho e no ano de 2005 as cultivares de melhor desempenho foram a DKB 350, e GNZ 2005

A adoção da maior dose de fertilizantes não proporciona incrementos significativos na produtividade de grãos de milho, porém provoca redução na porcentagem de plantas acamadas e quebradas.

A densidade de 55.000 plantas $\mathrm{ha}^{-1}$ proporciona a maior produtividade de grãos.

\section{REFERÊNCIAS BIBLIOGRÁFICAS}

BRASIL, E. C.; ALVES, V. M. C.; MARRIEL, I. V.; PITTA, G. V. E.; CARVALHO, J. G. Matéria seca e acúmulo de nutrientes em genótipos de milho contrastantes quanto a aquisição de fósforo. Ciência e Agrotecnologia, Lavras, v. 31, n. 2, p. 704-712, 2007.

BROCH, D. L. Milho safrinha: resultados de pesquisa e experimentação. In: FUNDAÇÃO MS PARA PESQUISA E DIFUSÃO DE TECNOLOGIAS AGROPECUÁRIAS, 1999, Maracajú. Anais... Maracajú: Fundação MS, 1999. p. 32-35.

CANTARELLA, H.; DUARTE, A. P. Tabela de recomendações de adubação NPK para milho safrinha no Estado de São Paulo. In: SEMINÁRIO SOBRE A
CULTURA DO MILHO SAFRINHA, 4., 1997, Assis. Anais... Campinas: IAC, 1997. p. 65-70.

COMPANHIA NACIONAL DE ABASTECIMENTO.

Levantamento de dad os. Disponível em: uwww.conab.gov.bri

DUARTE, A. P. Avaliação de cultivares de milho safrinha na região paulista do Vale do Paranapanema. In: SEMINÁRIO SOBRE A CULTURA DO MILHO SAFRINHA, 3., 1995, Assis. Resumos... Assis: IAC/CDV, 1995. p. 142-152.

DUARTE, A. P. Milho safrinha: característica e sistemas de produção. In: GALVÃO, J. C. C.; MIRANDA, G. V. (Eds.). Tecnologias de produção do milho. Viçosa: UFV, 2004. p. 109-138.

FANCELLI, A. L.; DORADO NETO, D. Produção de milho. Guaíba: Agropecuária, 2000. 360 p.

FERREIRA, D. F. SISVAR - Sistema de Análise de Variância. Versão 3.04. Lavras: UFLA/DEX, 1999.

GALVÃO, J. C. C.; MIRANDA, G. V. Tecnologias de produção do milho. Viçosa: UFV, 2004.

GONZALES ALTUNA, J. G. Milho safrinha: cultivares, adubação e épocas de semeadura. Lavras: UFLA, 2000. 57 p.

LIMA, R. O.; MANTOVANI, E. E.; MIRANDA, G. V.; ADRIANO, R. C.; ANDRADE, J. J.; SOUZA, L. V.; GUIMARÃES, L. J. M. Desempenho de híbridos experimentais de milho com alta e baixa adubação no Cultivo de safrinha em Coimbra (MG). In: SEMINÁRIO NACIONAL DE MILHO SAFRINHA, 8., 2005, Assis. Anais... Assis: IAC, 2005. p. 245-249. 
MOLTOCARO, R. C. R.; DUARTE, A. P. Redução de espaçamento entre linhas, densidade populacional e queima foliar pela geada em duas cultivares de milho safrinha. In: SEMINÁRIO NACIONAL DE MILHO SAFRINHA, 8., 2005, Assis. Anais... Assis: IAC, 2005. p. 293-300.

RIBEIRO, P. H.; CRUZ, J. C.; GARCIA, J. C.

Características do sistema de produção de milho safrinha no estado de Goiás. In: SEMINÁRIO NACIONAL DE MILHO SAFRINHA, 8., 2005, Assis. Anais... Assis: IAC, 2005. p. 91-104.

SANS, L. M. A.; SILVA, F. A. da; AVELLAR, G. de; FARIA, C. M. de. Riscos climáticos de safrinha de milho nos estados de Minas Gerais, Goiás, Mato Grosso e Mato Grosso do sul. In: SEMINÁRIO
SOBRE A CULTURA DO MILHO SAFRINHA, 5., 1999, Barretos. Anais... Campinas: IAC/CDV, 1999. p. 21-37.

SILVA, V. A. da; BUENO, J. F.; ARAÚJO, N. B. Avaliação de cultivares de milho em condições de safrinha no Estado de Goiás. In: SEMINÁRIO SOBRE A CULTURA DO MILHO SAFRINHA, 4., 1997, Assis. Anais... Campinas: IAC/CDV, 1997.p. 167-170.

VALOIS, A. C. C. Eficiência comparativa de quatro métodos de seleção em uma população melhorada de milho (Zea mays L.). 1992. 78 f. Tese (Doutorado em Genética e Melhoramento de Plantas) - Escola Superior de Agricultura Luiz de Queiroz, Piracicaba, 1992.

VIÉGAS, G. P. Melhoramento do milho para condições adversas. Campinas: Fundação Cargill, 1989. 44 p. 